\title{
Reform of the University Curriculum in Usability: A Case Study Implementing an Integrative Approach
}

\author{
Yevgeniya AMELINA, Erkki SUTINEN, Seppo HELLE \\ Department of Computing, University of Turku, Turku, Finland \\ e-mail:yevgenia.amelina@gmail.com,erkki.sutinen@utu.fi,seilhe@utu.fi
}

Received: June 2021

\begin{abstract}
User-centricity and usability are a premise of digitalization, a current trend for business model innovation based on advanced digital technologies. The article addresses a gap in the literature, in which descriptions of the cases of updating university curricula in usability are lacking. This gap also exists in the practice. The study uses the example of a project for revising the content of usability courses at the University of Turku as a case. The research objective is to explore an integrative approach to usability education. For this, we consider the data collected via interviews with the faculty teaching usability subjects. Thematic analysis is applied to examine the interview outcomes. Recommendations as to updating usability curricula are provided.
\end{abstract}

Keywords: user experience, usability, curriculum update, semi-structured interview, thematic analysis.

\section{Introduction}

\subsection{User-Centricity as a Premise of Digitalization}

Parida (2018) describes digitalization as a fundamental disruptive force triggered by the Fourth Industrial Revolution and the Internet of Things, which has changed the way business processes and activities are conceptualized, leading to the redesign of the relationships between organizations and customers and implementation of new business models, placing advanced technology at the heart of all processes, products, and services, and calling for agility, speed, flexibility, and the ability to pivot rapidly to pursue new business opportunities and keep up with a highly volatile global business environment.

Digitalization causes changes for businesses due to the adoption of digital technologies in the organization or in the operation environment (Parviainen et al., 2017), while 
Parida (2018) elaborates that it enables servitization, a transition from the traditional provision of products and basic services to the delivery of higher-value advanced services.

The focus of digitalization, as the phenomenon which places digital technology at the core of a business model, is user-centered approach, thus for software engineers, digitalization means that they are expected to assist the clients to create sophisticated digital services (see, e.g., Cheng et al., 2011; Hienerth et al., 2011; Yazidi et al., 2011; Yelmo et al., 2011). Brenner et al. (2014) view the digital user as a new design perspective in business and information systems engineering (BISE) and posit that the ubiquity of information technology leads to a fundamental shift in the BISE, requiring the individual user and his or her demands to become the focus of all efforts.

Due to digitalization, user-centricity in the process of software development, which encompasses the dimensions of understanding the user's demands and an ability to cooperate with the user to achieve the desired result, has become a crucial competence for the software engineers, usability professionals, and specialists in BISE alike. It is now required alongside technical, application domain (business), coordination and project management, communication, collaboration, and intercultural competencies discussed in Holtkamp and Pawlowski (2015), and innovation competencies, identified in AndreuAndres et al. (2018), which are classified into creativity, critical thinking, initiative, teamwork, and networking.

However, definitions of user-centricity vary.

Hertzum and Clemmensen (2012) report on a study of usability professionals that solicited the constructs they apply when thinking about systems use. The results of the interviews with 24 Chinese, Danish, and Indian usability professionals indicate that goal-related performance is crucial for their thinking about usability and that they tend to view it at an individual level, rather than at organizational and environmental levels, while considerations regarding users' cognitive activities appear to them more significant than human-factors knowledge about their sensorial abilities.

Alonso-Ríos et al. (2009) present a critical analysis and a taxonomy for usability, pointing out that the concept is derived from the term "user-friendliness," or "an expression used to describe computer systems which are designed to be simple to use by untrained users, by means of self-explanatory or self-evident interaction between user and computer" (Chandor et al., 1985, p. 472).

Gulliksen et al. (2003) offer a definition of user-centered systems design (UCSD), which is based on 12 key principles for a user-centered development process, deriving from the existing theory and practice of software development projects.

For the purposes of this research, we adopt the explanation proposed by Patton (2007), who emphasizes that user-centricity goes beyond a systematic effort to understand the user's requirements: instead, digitalization entails co-designing with the user to reach a joint informed decision regarding the software, or, rather, the digital service that they seek.

The user-centered method has numerous manifestations and is applied in areas as diverse as user data protection (e.g., Bestavros et al., 2017), online shopping (Dabrowski \& Acton, 2013), digital marketing (Corrigan \& Miller, 2011), 5G networks (Monserrat et al., 2016), media research (Costa, 2014), mobile cloud computing (Dijiang et al., 2013), and e-learning (Huang \& Shiu, 2012). 


\subsection{Overview of Related Literature. Frameworks of Teaching Usability}

As the ever-changing technological landscape reflects psychological, sociological, and cultural characteristics of the users, universities and professional bodies like the Association for Computing Machinery (ACM) are challenged to keep their curricula up to date. A multidisciplinary approach is applied, since the field of user experience draws upon ergonomics, psychology, design, managerial science, and business, among others. In a global survey with 339 participants by Churchill et al. (2013), respondents agreed that cognitive science, design, and philosophy are crucial subjects for the content of user experience courses, while accessibility, teamwork, social computing, social media, and ubiquitous computing are the most significant topics in HCI, and Agile/iterative design is the indispensable method to be taught. On the other hand, the interviewees mentioned that although a uniform curriculum or degree would be beneficiary for both students and industry professionals who employ them, "a common language seems to be lacking" (Churchill et al., 2013, p. 49).

An overview of the approaches to teaching UX, HCI, and IxD identified in the literature is presented in Table 1.

Table 1

Frameworks of teaching usability

Source Essence of the multidisciplinary educational model

Koutsabasis and Vosinakis (2012)

Sundblad et al. (2006)

Mackay and Fayard (1997)

Faiola and Matei (2010)

Altay (2014)

Cooke and Mings (2005)

Breuch et al. (2001)
An HCI design studio course: HCI methods, design practice, and technology are combined between a real and virtual design studio; constructivist pedagogies are united with virtual worlds

A project course on user-oriented interaction design: guest lectures by specialists in industrial design, psychology, anthropology, ethnology, HCI, computer science, and cinema studies are followed up by practical exercises

A course encompassing HCI, natural science, and design

Suggest augmenting human-computer interaction design (HCID) education with teaching affordance design for mobile devices; affordance, which offers to the user a particular kind of the product functionality, is the fundamental component of the pedagogical model: in line with cognitive theory, users interact with mobile devices by constructing mental models of their functions, starting with physical appearance

A course on human factors that applies learner-centered methods to user-centered design teaching, drawing upon the parallels between the two approaches

Cite the outcomes of 12 interviews conducted at Microsoft to find out the specialists' views on usability education and research: UX teaching needs to be extended to include additional usability evaluation methods; students need critical and communication skills when they enter the workplace

Draw a connection between technical communication and usability teaching: both emphasize audience analysis, technology, and information design 
Table 1 - continued from previous page

\begin{tabular}{ll}
\hline Source & Essence of the multidisciplinary educational model \\
\hline Ludi (2005) & $\begin{array}{l}\text { Elective seminar for software engineering undergraduates; analyzes approaches } \\
\text { to teaching software testing via hands-on activities: planning the methodology, } \\
\text { recruiting participants, performing the testing, and analyzing the results }\end{array}$ \\
Mitchell et al. (2020) & $\begin{array}{l}\text { Present an innovative pedagogy for designing digital touch communications, } \\
\text { developed through an interdisciplinary collaboration of HCI, Industrial Design, } \\
\text { and Social Science academics. Discuss the role of low-fidelity experience } \\
\text { prototyping of digital touch interactions beyond screens }\end{array}$ \\
\hline
\end{tabular}

\subsection{Structure of the Article}

The study sets out with an introductory chapter on user-centricity as a premise of digitalization, which includes a brief literature review of the extant approaches to teaching courses in usability.

Chapter 2 is devoted to the research design. It elaborates on the method and process of conducting in-depth semi-structured interviews with the faculty of the Department of Computing of the University of Turku as the technique for collecting empirical data.

Chapter 3 covers the process and outcomes of the analysis of the data. The answers are systematized to explore common themes and discrepancies in the opinions. Thematic analysis is employed to identify points of convergence as to developing the basic curriculum in $\mathrm{UX}, \mathrm{HCI}$, and $\mathrm{IxD}$.

The article concludes with a discussion of the interview findings and answers to the research questions. Based on the thematic analysis of the interviews with the faculty, recommendations for updating university curricula are provided. Finally, directions for further research are identified.

\section{Research Design}

\subsection{Research Problem}

As the previous chapter shows, the trend of digitalization has placed user-centricity in the spotlight of the efforts of specialists in software engineering. As the user-centric approach has become the focal point of software development processes, new competencies are required of the professionals. Literature discusses both new technical and non-technical skills that graduates of educational programs in software engineering, usability, and BISE are expected to possess to be able to respond to the challenges of digitalization. However, there is a scarcity of research on how educational programs should respond to these updated requirements. There are different approaches to this problem, and various surrounding factors like the background and targets of the students and composition of the curricula may affect the quality of the outcome. While exploration of the 
ways in which societal and professional challenges of digitalization can be addressed in software engineering education is outside the scope of this article, it contributes a practical case of the approach taken to updating the basic course offering in usability by a university with technological profile.

\subsection{Research Questions}

The article seeks to answer the following set of research questions:

1. What topics are indispensable to be included in user experience courses?

2. What approaches to teaching UX programs can be borrowed from the experience of the universities worldwide?

3. How can applicable elements in the fields of business and marketing, design, information and knowledge management, information behavior, psychology, and communication studies be incorporated into UX education?

4. What recommendations can be made for developing content of the courses in UX/ HCI for the universities with technological profile, based on the experience of the University of Turku?

\subsection{Research Context and Approach}

The article considers the example of a project for updating the usability curriculum at the Department of Computing of the University of Turku (Department of Future Technologies at the time of the research), implemented in the course of September - November 2018. As an outcome of the project, a course in usability, user experience, and analytics was developed in 2019-2020. The first author worked at the university as a project researcher. The empirical data for the study was collected via in-depth personal interviews with lecturers and researchers responsible for developing usability curriculum.

The interviews were conducted in September - October 2018 and followed a semistructured procedure: while each participant was presented with the interview guide and answered the same set of questions in the same order, in a few cases, where the answers held potential for elaboration, follow-up questions were asked by the interviewer.

A qualitative research methodology of in-depth interview was selected as the study design for several considerations. First, because of the open-ended nature of the questions, it allowed to elicit from the interviewees rich accounts of their perspectives regarding the need to introduce new topics and courses on UX, HCI, and IxD. The open-ended questionnaire was designed to allow the respondents freedom in sharing their views on the topic. However, it also provided structure to the talks, so that the interlocutors did not deviate from the focal issues discussed.

Deep understanding of the positions regarding the redesign of the curriculum and the practical formats of introducing changes to the content of the courses was sought. The focus of the interviews was on understanding the varying viewpoints regarding the issue of curriculum reform, which was sensitive for the respondents, and on exploring 
facets of their argumentation and propositions - i.e., on grasping an aspect of social reality via investigation of its interpretation by its participants. The meaning-making occurred during the interviews in the course of interaction between the researcher and the subjects.

Analysis of data in the present study was driven by the views of the respondents. The analytical effort concentrated on reconstructing the social reality of the interviewees shared in response to the semi-structured questionnaire.

The focus of the study was on understanding behavior (how the respondents would have gone about implementing changes to the curriculum), values (whether they see course redesign as a priority), and beliefs (the perceived efficacy of the faculty in introducing the innovation to the course offering), rather than on generalizability to the wider populations.

Further, the choice of the methodology was conditioned by the fact that the researcher aimed for close contact with the subjects and involvement in the social setting from which the respondents were recruited. The project researcher was a full-time Master's degree student in Governance of Digitalization at Åbo Akademi University and had a background in teaching international business at a university specializing in business and IT. The chosen data collection method allowed the investigator, who was immersed into the setting for three months, to share the context of the practitioners who answered the questionnaire, rather than acquiring a remote approach characteristic of quantitative research, in which the researcher is often distantiated from the social milieu of the studied subjects.

Finally, flexibility of the study design was another valuable characteristic of the applied qualitative approach. In addition to the questionnaire, follow-up questions allowed to grasp extra facets of the interviewees' standpoints.

\subsection{Research Methodology}

The interview guide, that comprised ten open-ended questions, asked each participant to detail the proposed changes to the learning activities and outcomes while expanding the content of the courses or creating a new discipline. The interviewees responded to a set of questions that concentrated on the following key topics:

- The skills related to user experience demanded by the job market.

- The international best practices in teaching UX, IxD, and HCI that can be borrowed.

- The practice of interdepartmental programs.

- The module of the taught disciplines to be developed in response to the digitalization trend.

- Various configurations of the topics from the fields of technology, business and marketing, design and art, information studies, psychology, and communication science to be adopted in the teaching practice.

The answer to each of the research questions (RQ) is based on several questions of the interview guide. The correspondence is as follows: the answer to RQ1 is derived 
from the answers to interview questions 2 and 3, the response to RQ2 is informed by the answers to question 4, the reply to RQ3 is established by the answers to questions 7, 8, and 9, while RQ4 is answered based on the responses received to questions 2-10.

Each interview lasted between 40 minutes and one hour. The answers were video recorded and transcribed.

\subsection{Collection of Data}

A total of eight interviews were conducted. As the method of selecting the respondents, the interviewer used purposive sampling, i.e., lecturers and researchers interested in the topic of modernizing the usability curriculum were targeted and approached with an invitation to be interviewed. Purposive sampling was applied, because accounts by individuals possessing specific expertise were aimed for. A characteristic sought after was a willingness to review the content of the existing courses and an interest in redesigning the course offering to take into account recent trends and the international best practices in teaching in the field. The prospective respondents received a call for participation over e-mail that briefly introduced the essence and purpose of the project for developing the curriculum and of the interviews. The invitation was originally e-mailed to 15 lecturers and researchers responsible for teaching usability-related courses and for otherwise contributing content to the disciplines. Eight of the contacted specialists consented to participate in the interviews.

Instructors teaching both Bachelor's degree and Master's-level courses were contacted and included in the sample. The background of the respondents included teaching and research in the areas like software engineering, software development process modelling, gamification, interaction design, software testing, distributed systems, software architecture, web and mobile programming, object-oriented programming methodologies, user interface design, advanced programming techniques, and functional and declarative programming. They varied considerably in terms of the teaching and research experience: from 1.5 to over 20 years ( 1 respondent each). Their positions ranged from a university lecturer to a chairperson of a unit.

\subsection{Data Analysis Approach}

After each interview session, the interviewer interpreted the received information by identifying agreements and disagreements among the respondents and extracted the key types of course content envisioned by the interviewees.

Thematic analysis of the full transcripts of the responses to the 10 questions of the interview guide was applied to explore the interviewees' reasoning. The technique allowed to identify common themes that were proposed by most of the participants for including into the content of the existing courses or into a new discipline to be produced. Potential drawbacks of expanding the curricula by incorporating the new course components were also detected during analysis of the interview data. 
The interviews uncovered new thematic areas that the respondents deemed necessary to include into the updated curriculum, and the types of learning activities that might be introduced. The selected analysis method enabled these reflections to be fully explored and systematized.

\section{Analysis of the Empirical Data}

\subsection{Thematic Analysis of the Interview Responses}

Interview question 1 asked about the disciplines pertaining to $\mathrm{UX} / \mathrm{HCI} / \mathrm{IxD}$ that the respondent was responsible for and the overall duration of the teaching experience for each of the courses, and is therefore not included in the analysis. Each question is presented separately, followed by an elaboration on the responses, in alignment with the research questions. Detailed answers to the questionnaire are available as an online appendix to this article at https://tt.utu.fi/en/appendix-an-integrativeapproach-to-usability-education/.

Interview questions 2 and 3 form the basis for the reply to research question 1.

Question 2: In each of your subjects, what are the three crucial skills that the students are most likely to apply in their practice immediately after graduation?

Appendix 1 summarizes the answers received to question 2 from the 8 respondents.

Question 2 elicited disparate opinions from the respondents, who overall ranked technical skills, team management, and ensuring the best user experience via an ability to apply a user-centered approach to software development highest among the requirements. A notable tendency was to pinpoint non-technical skills alongside technical competencies. Several respondents were hesitant to choose 3 crucial skills and instead named a range of abilities.

Respondent 6 shared: "My list of three skills, I guess, would be the team skills, then, one should have a really good understanding about programming... But what should I raise for a third skill? Maybe it's design, and I am really thinking architectural design, user interface design..."

Question 3: While you were teaching the subject(s), has the job market generated demand for new skills that are now indispensable for the specialists in UX/HCI? If so, what are those?

A synthesis of the responses to question 3 is given in Appendix 2.

Question 3 of the interview guide concerned new demands of the job market regarding the skills of the graduates specializing in UX and HCI. As in the case of question 2, the respondents elaborated on both technical and non-technical competencies, and, as Appendix 2 shows, there was a lack of consensus among them. An aspect on which the opinions coincided was availability of new platforms for software development, which 
has equipped software engineers with better tools. Respondent 1 summarized this in the following way: "The platforms we are using to create the software, create the user interfaces, have become more advanced regarding the user interaction, they have become easier to use, so basically the developers now have better tools to respond to this demand, and that is something we have to teach here also. So maybe that is the biggest thing that has changed."

Another aspect on which the views of several of the respondents converged was achieving the best possible user experience.

The reply to interview question 4 informs the answer to the research question 2.

Question 4: If you were revising the content of the courses related to UX currently offered by the University of Turku, what new approaches and methodologies of teaching these disciplines employed by other universities in Finland and abroad would you implement in the first place?

The answers to question 4 are provided in Appendix 3.

Question 4 concerned the international best practices in teaching UX that the respondents deemed applicable to implement at the University of Turku. An interesting observation was that most of the participants hesitated to name the exact university programs or courses that might be regarded as the role models for updating the curriculum. However, an array of advanced teaching methodologies was named without mentioning an exact course, program or educational institution.

A common theme mentioned by the respondents was introduction of new technologies, which in their opinion need to be scrutinized in the teaching process. According to respondent 7, “Another thing that I've been thinking is that we could introduce new platforms on the course like touch screens and virtual reality and augmented reality glasses, and the focus should be on how to actually use those things in terms of programming languages."

The opinions of the rest of the respondents diverged considerably: the new teaching approaches named by them ranged from an increased attention to practical works, to using MOOCs and lecture videos (the so-called "flipped classroom") as the course delivery techniques, software testing with actual users, and the practice of working in small groups to be applied more widely. Taking a more general approach, one of the respondents also mentioned that it is worthwhile to learn from the foreign programs that concentrate on user interaction and graphical design as a source of advanced modern teaching approaches and methodologies.

Research question 3 is answered based on the replies to interview questions 7-9.

Question 7: Do you see the need to integrate components of the curricula in the fields of business and marketing into the content of the course(s) that you are teaching? How would you implement these adjustments?

Question 8: Do you envision ways of integrating components of the curricula in the fields of design and art into the content of the course(s) that you are teaching? How would you accomplish this? 
Question 9: Do you consider that fragments of the curricula in the fields of information studies (e.g., information behavior, information and knowledge management), psychology, or communication science (e.g., media literacy, social media) need to be incorporated into your current courses? Please describe the changes that you would make in detail.

Since questions 7-9 concerned related aspects of introducing additional content to the current curriculum, the answers to them are grouped in Appendix 4.

Questions 7-9 concerned incorporating fragments of the curricula in the fields of business and marketing, design and art, information studies, psychology, and communication science into the current course offering. The respondents offered several configurations of merging the curriculum components, and differed in the comparative weight assigned to the various aspects. Overall, the respondents tended to accentuate either the business and marketing aspects, or the topics from design and art, and consented that psychology is an area from which study content should be borrowed, as it informs UX and HCI.

A typical reply was given by respondent 8, who emphasized: "In the project course some of the solutions built are not built for commercial use. They may be built for a research group to utilize as part of their work, they may be built to help the doctors in the hospital. In a monetary world that could be converted to business, but making business with that is a bit distant. And the problems themselves are huge enough, so that we are not asking the students how to make business out of the solution, but first to understand the field, to understand the problem, and design a solution for it." Commenting on the need to integrate components of art and design, respondent 7 mentioned: "The teachers could think about this more. I think this is a real tragedy that we are focusing so much on engineering, and the students from Human Sciences and Art and maybe Design... don't really feel comfortable attending computer engineering, computer science courses, because they don't have any common ground... For example, if we think business cases, this is where design and art meet the engineering design, some areas that can lead to new products and sell quite well." Describing integration of the topics from information studies, psychology, and communication science, respondent 5 accentuated: "I believe that all of these have at least some kind of application areas, that we could quite easily give some examples, when we are going through some cases in the lectures... For example, what kind of distributed systems exist - then we could mention some of these application areas, like social media. There are also many applications of information and knowledge management in the distributed systems, so cases are one way to incorporate these fields in the courses, and also, of course, the exercise projects..."

Finally, responses to the interview questions $2-10$ provide the background for replying to the research question 4 .

Question 5: Considering the current demands of the job market, do you see benefits for the graduates of the programs in UX/ HCI that are jointly offered by several departments, e.g. schools of engineering and schools of management? Why or why not? 
Synthesized responses to question 5 are given in Appendix 5.

When answering question 5 , which deals with the benefits of usability programs jointly offered by various departments, the respondents touched upon a range of themes. The first one concerned pursuing the advantages of a multidisciplinary approach in both the organization of the courses and in involving students with different backgrounds as part of the project teams. Thus, respondent 4 commented: "I see a benefit of joint courses with different departments, because now in many courses our students are really homogenous, it's the different types of developers doing things together, that narrows their mindset. But if they work with people who don't think about programs as lines of code, and CPU cycles, who see them only as tools to do something, that would be beneficial to them, because that's what they will be doing in actual companies, companies where you are not just programming something in your office, when you advance to becoming a consultant or an on-site developer, what you do is you communicate with people outside your own safe corner."

However, there was no unanimity among the respondents as to the mechanisms and overall viability of implementing joint interdepartmental programs: while some spoke in favor of cooperation with institutions in the sphere of design, rather than with schools of management or business, according to others, the combination of efforts is more applicable in the case of start-up companies, where business and marketing expertise are at the forefront. One respondent was an advocate of the approach, pointing out that it is especially applicable to UX, as it combines expertise from design to management science, business, and psychology.

Question 6. If you were to develop a new module for your discipline that in your opinion would best prepare the graduates to meet the demands of the digitalization trend, which topic(s) would you focus on and why? Please describe the potential content of the module, the type of learning activities, and the expected learning outcomes.

Appendix 6 lists the answers to the question regarding a new module that would keep the students abreast of the digitalization requirements.

The respondents, again, displayed varying opinions. One aspect on which they coincided was that the hypothetical module should include topics like usability and user experience.

A range of techniques for implementing the module that would cover the topic of digitalization were suggested. According to one of the respondents, the delivery of such a module should center on real-life exercise projects with participation of the industry partners, while another envisioned an experimental module or course, in which the students would be applying new platforms, new input and output devices, and new ways of interacting with the systems. One interviewee accentuated that digitalization is a wide field spanning different lines of business, industry, commerce, and public services, so on the project course that he taught he offered these aspects as separate project topics for the students to choose from: "Maybe a personal opinion, I doubt that we can cover the whole field, but we provide these projects from different fields, so the students familiarize themselves already during their final year with them." Further, one respondent 
pointed out that the web is such a big and popular execution platform, used also for the government's new digitalization projects and services, that these aspects deserve greater attention in the teaching process.

Question 10: Academic institutions worldwide are currently exploring various models of integrating the curricula pertaining to technology, business, design, and art. In your opinion, is this approach applicable to teaching your course(s)? How would you apply it in developing the content of the discipline?

Replies to question 10, which summarizes the integrative approach, are presented in Appendix 7.

In answering question 10, which concerned the vision for combining curricula in the fields of technology, business, design, and art, the respondents were almost unanimous that there are ways of integrating such material within the courses they taught. Their approaches, however, differed.

An apprehension of diluting the core curriculum, which should concentrate on the technological skills, by introducing the additional content was expressed by two respondents. One of the respondents, whose opinion echoes those of the majority of his colleagues, stressed the technological side of things, but believed that certain decisions have an impact on the business outcomes, for example how long and costly the development process is, and what that means for maintaining the product lines.

Another interviewee shared that while business creates contexts for ICT professionals to act in, when creating user interfaces, they need to possess more pragmatic skills. He accentuated the skills in design and art from the proposed array.

Several respondents mentioned that the combination of expertise from technology, business, design, and art is already being implemented to some extent in the current courses.

In two interviews, the approach was again viewed as applicable, but ways of implementing it remained an open-ended question. A respondent thought that exercise projects would be a natural venue for integrating the four topics, and that examples of such systems where the design and art side of things are a very significant part of the delivered system should be shared. According to another, when new technological ideas are produced, it is necessary to validate how much they would make money, what are the risks, how expensive they are to implement, and what the business case is. In this sense, the topics from business are indispensable. One of the interviewees shared that the way to go is to establish multidisciplinary student teams. The four topics are therefore prominent in the project course he teaches, but they are not embedded as structural elements. Respondent 2 provided the following explanation of his standpoint: "In the beginning it's more about the technologies, that's the first thing you have to master, learn the skills. Design and art are something that quite naturally comes with that. So those three, technology, design and art are very important at the beginning, and business is something that comes later on, at least that's my experience..." 


\subsection{Suggested Implementation Techniques for Curriculum Redesign}

Table 2 presents ten scenarios, or pedagogical approaches, for implementing changes to the curriculum that emerged from the interviews.

Table 2

Implementation Techniques for Curriculum Redesign

\begin{tabular}{ll}
\hline $\begin{array}{l}\text { Implementation } \\
\text { scenario }\end{array}$ & Description \\
\hline $\begin{array}{l}\text { 1. Practice-oriented } \\
\text { collaboration course }\end{array}$ & $\begin{array}{l}\text { The first suggested method of integrating new material into the disciplines was } \\
\text { a practice-oriented collaboration course aimed at incorporating elements of the } \\
\text { curricula in the spheres of design and art into the taught content through cooperation } \\
\text { with design schools and programs. The course centers on the idea of partnership with } \\
\text { the educational programs that profoundly study various topics in the area of design. The } \\
\text { approach was suggested by one of the respondents based on his experience in running } \\
\text { a collaboration course with Uniarts. The course brings together artists and students, } \\
\text { who join forces to implement mixed reality solutions that are connected to art. }\end{array}$
\end{tabular}

2. Exercises in small groups

3. Interdepartmental program or courses

4. Interim projects integrated into the courses

5. Additional courses or a minor subject
Three interviewees supported the second suggested approach, working in small groups, pointing out that it creates the context for learning by doing, which is indispensable for teaching software development. Exercises in small groups were offered as venues for integrating the content from business, design, and art curricula. One of the interviewees envisioned that the format would replicate the courses used by the universities abroad that aim at activating the students by exercises and working in small groups. He saw the technique as beneficial, because it provides a proper environment to foster the process of learning by doing and of trying out various approaches.

Interdepartmental cooperation programs were discussed by 7 participants, who accentuated that the method is especially relevant in teaching UX, as it combines knowledge from a variety of disciplines. This format was also seen as a way of overcoming the homogeneity of students and of honing the skills in communication with non-developers. Several aspects were further mentioned as benefits. In particular, one of the respondents commented that interdepartmental cooperation is useful in that it involves the students in real-life projects that are not made up by the lecturers. These views were shared by another respondent, who also said that one benefit of multidisciplinary courses is that they bring together opinions of different stakeholders. According to the respondents, interdepartmental programs and courses provide a valuable opportunity to practice skills in communicating with the users.

The respondents further suggested the approach of interim projects following the format of the Capstone exercise, but on a smaller scale, interspersed throughout the study programs. The smaller projects replicating the Capstone activity would concentrate on creating and implementing an idea for an application, following the product life cycle through to having a complete piece of software with an installation package ready to be disseminated. The interviewees believed that it does not suffice to have one big project in a Capstone course, but it is beneficial to implement smaller projects throughout the studies to practice the skills on a smaller scale.

Two respondents spoke about additional courses taken from the relevant departments, e.g. in psychology, media literacy, and communication science, or a minor subject, as a means of integrating new content. 
Table 2 - continued from previous page

\begin{tabular}{|c|c|}
\hline $\begin{array}{l}\text { Implementation } \\
\text { scenario }\end{array}$ & Description \\
\hline $\begin{array}{l}\text { 6. Cooperation with } \\
\text { the industry partners }\end{array}$ & $\begin{array}{l}\text { Involving partners from the industry to teach portions of the courses was also } \\
\text { discussed, in particular as a means of getting exposure to real-life projects. One of } \\
\text { the respondents spoke about involving industry expertise and integrating it into the } \\
\text { content of the courses, especially the one dealing with web programming. }\end{array}$ \\
\hline 7. Study module & $\begin{array}{l}\text { The respondents proposed a new study module that would focus on usability to be } \\
\text { developed in order to integrate new content within the existing disciplines. One of } \\
\text { the respondents shared that if he were to build a new module to meet the demands of } \\
\text { digitalization trend, he would include the topics of distributed systems and usability. He } \\
\text { envisioned the module as being less technical than the existing User Interfaces course, } \\
\text { with usability aspects and psychological sides of user experience incorporated. }\end{array}$ \\
\hline 8. New course & A separate course on user experience was offered as a solution by two respondents. \\
\hline 9. Case studies & $\begin{array}{l}\text { Another mentioned pedagogical approach to developing the curriculum was } \\
\text { introduction of case studies highlighting examples of digitalization projects, in which } \\
\text { an implemented algorithm helped achieve a business goal. Digitalization case studies } \\
\text { showcasing implementation of digital technology at the core of a business model } \\
\text { were suggested to be included into every course that teaches theoretical platforms and } \\
\text { backgrounds, for example, machine learning. }\end{array}$ \\
\hline $\begin{array}{l}\text { 10. Multidisciplinary } \\
\text { student project teams }\end{array}$ & $\begin{array}{l}\text { Establishing multidisciplinary student teams that would bring together expertise from } \\
\text { different backgrounds and majors to implement projects was advised. According to } \\
\text { the respondents, this method provides an essential exposure to a variety of skill sets } \\
\text { and viewpoints, and allows to foster creative thinking and hone cooperation skills of } \\
\text { the project participants. }\end{array}$ \\
\hline
\end{tabular}

Revisions and changes of the course and curricula content to include additional components can be referred to as content- or discipline-oriented integration. Instances when the content of the courses remains unchanged, but there is integration in practice, via corresponding study activities or composition of the study groups, can be described as real-life integration. The suggested 10 pedagogical approaches to expanding the curriculum to include additional types of content can be ranked along the dimensions of content- and discipline-oriented integration and real-life integration, and accordingly mapped to a system of 4 quadrants presented in Fig. 1.

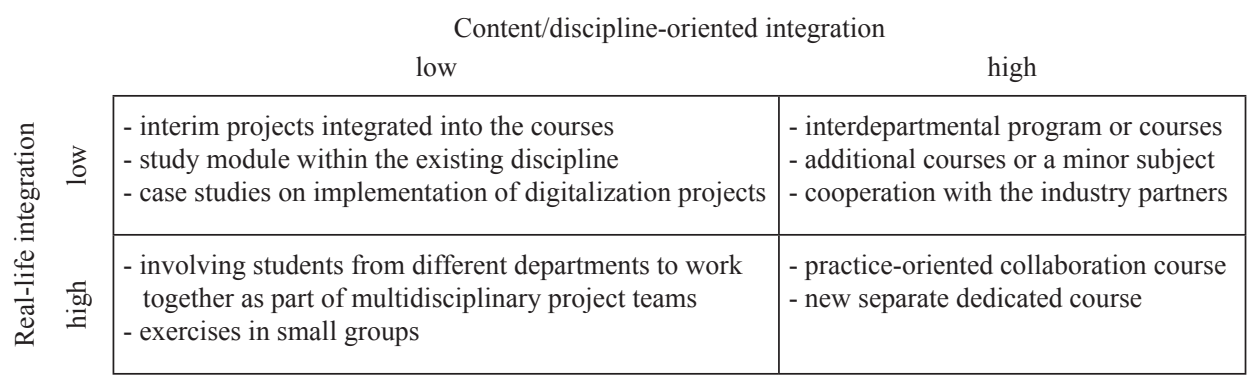

Fig. 1. Mapping the suggested teaching methods along the dimensions of content-oriented and real-life integration. 
As Fig. 1 shows, the pedagogical approaches characterized by a low degree of content-oriented and real-life integration include interim projects integrated into the courses, a study module within the existing discipline, and case studies on implementation of digitalization projects. The suggested methods with a high level of content-oriented integration and a low degree of real-life integration are interdepartmental program or courses, additional courses or a minor subject, and cooperation with the industry partners. The techniques at the intersection of little content- and discipline-oriented integration and a considerable real-life integration are involving students from different departments to work together as part of multidisciplinary project teams and exercises in small groups. Finally, a practice-oriented collaboration course and a new separate dedicated course are characterized by a high level of content-oriented and real-life integration.

\section{Discussion}

\subsection{Main Findings from the Interviews}

The key findings from the interviews were as described further.

There was a consensus among the respondents regarding the need to include user experience, user-centered design, and usability among the topics covered by the courses or as a separate course. Five out of eight interviewees ranked user experience among the three skills that the students are likely to apply in the workplace immediately after graduation, on a par with technical skills and team management. User experience was mentioned by four participants in response to the question about the new skills demanded by the job market. Three interviewees also named user experience among the topics to be included into the content of a new module that would consider the demands of the digitalization trend.

A surprising result of the interviews was that the respondents failed to name foreign universities hosting programs which might be viewed as examples of the best practices to adopt. However, they mentioned advanced techniques for teaching usability implemented by the universities worldwide. As far as best practices are concerned, they highlighted the following approaches and techniques: intensive programs that concentrate on user interaction and graphical design, working in small groups, MOOCs, "flipped classroom," software testing with actual users, and practical works. A conclusion from these findings is that active learning pedagogies should be applied in the redesigned courses.

The question about possibilities of integrating the content in the fields of business and marketing divided the respondents. Four of them advocated for including the topics, while the other four did not see ways of merging the content. The proponents cited arguments like the necessity to think about software monetization already at the development stage and the need for the students to understand how much they are generating costs and what they are bringing in. The suggested formats were a course in software business and business cases. 
A significant finding from the interview responses is that team management and teamwork skills were ranked high by the respondents. Teamwork was highlighted by 5 interviewees as a crucial professional skill that the graduates should possess, alongside technical skills. Besides, teamwork was mentioned as a new skill related to UX and HCI demanded by the market. An implication of this result is that group projects emphasizing teamwork should be included into the content of the courses in usability that are being redesigned.

An interesting finding was that familiarity with new platforms for software development was mentioned among the new skills demanded by the job market. Two participants were convinced about its topicality. The theme also came up in the responses to the question about the best practices in teaching UX implemented by the universities worldwide, mentioned by 2 participants. Therefore, new platforms need to be taught as part of the refactored courses.

Seven respondents viewed interdepartmental programs as being beneficial and applicable especially to the field of UX, which is multidisciplinary. In their opinion, the approach brings several advantages to teaching UX and interaction design, including cooperation with diverse partners, fostering communication skills with non-developers, real-life exercise projects, and exposure to the various stakeholders' viewpoints in the process, so it should be applied when redesigning the courses.

The following composition of the module to be created to respond to the digitalization demands was suggested: user experience skills (mentioned by 3 respondents), graphical skills, cooperation within cross-discipline teams, usability testing with actual users, distributed systems, web programming, and various aspects of digitalization (1 respondent each). These findings indicate that this combination of skills needs to be implemented so that the courses keep abreast of the digitalization requirements.

It was found that all the respondents support the idea of including fragments of the curricula in the fields of design and art. They were thought of as pertinent, for example, in game design, game testing, user interface design, and in the broader process of system implementation.

Psychology was viewed as a field to adopt topics from by seven interlocutors, who highlighted it as an area from which human-computer interaction draws extensively. The findings also indicate that portions of the curriculum in communication science seemed pertinent to four respondents. Two participants spoke about the need to include content from information studies.

From the authors' standpoint, an important finding from the interviews was the suggestion to include case studies in various aspects of digitalization into the content of the theoretical software engineering courses. This innovation puts digitalization into the spotlight for software engineering professionals and helps acquire a practical perspective on how an implemented software allows to achieve a business goal and innovate a business model.

A multidisciplinary approach to teaching UX, HCI, and IxD was mentioned by the majority of the participants, who commented on the various configurations of integrating technology, business, design, and art as part of the courses. As pointed out in the literature, UX, IxD, and $\mathrm{HCI}$ are multidisciplinary in their implementation, a view 
supported by the interview participants. The respondents were unanimous about a possibility to combine topics in technology, business, design, and art in the content of the courses they were teaching, but differed as to the techniques of making such additions. Four of them accentuated technology, design, and art and deemed business to be less relevant, while another four advocated for including business topics. The implication of these findings for updating the curricula is that the combination of topics from technology, business, design, and art is pertinent to be included as part of the study programs.

Finally, ten pedagogical approaches to integrating the content from business, marketing, art, and design were discussed during the interviews. Of these, interim smallscale projects following the format of the Capstone project integrated into the courses, a study module within the existing discipline, and case studies on implementation of digitalization projects are characterized by a low level of content- and disciplineoriented integration and a minimal real-life integration. On the other hand, a practiceoriented collaboration course and a new separate dedicated course on usability are described by high content-oriented integration and a high degree of real-life integration.

\subsection{Answers to the Research Questions.}

Recommendations as to UX Curriculum Redesign

Based on the analysis of the interview data, it is now possible to answer the research questions. The first question is "what topics are indispensable to be included in user experience courses?" The reply is based on the answers to questions 2 and 3 of the interview guide. The topics can be divided into those pertaining to "hard" and "soft" skills and vary from ensuring the best user experience, interaction design, new platforms for software development, full stack development, and software testing to team management, project management, presentation skills, academic writing, business skills, and change management.

The reply to research question 2, "what approaches to teaching UX programs can be borrowed from the experience of the universities worldwide?" is derived from the interview question 4 . The range of techniques to be adopted includes working with new devices and platforms, intensive programs that concentrate on user interaction and graphical design, working in small groups, MOOCs, lecture videos ("flipped classroom"), software testing with actual users, and practical works.

Interview questions 7-9 shed light on the 3rd research question, "how can applicable elements in the fields of business and marketing, design, information and knowledge management, information behavior, psychology, and communication studies be incorporated into UX education?" The responses suggest that topics from design and art are to be integrated in the first place, followed by fragments of the curricula in the fields of psychology, business and marketing, communication science, and information studies. 
The 4th research question is "what recommendations can be made for developing content of the courses in UX/HCI for the universities with technological profile, based on the experience of the University of Turku?" The following guidelines can be proposed:

1. Make sure that the changes suggested for implementation are motivated: it is worthwhile to determine the skills that are in demand by the job market, as well as new tendencies regarding the skill sets, and to base the alterations to the curriculum on these indicators.

2. Ensure experiential learning opportunities: for the redesigned courses to be effective, active learning in the format of projects and small group assignments should be pursued alongside lectures and assigned readings.

3. Consider using advanced teaching techniques like the "flipped classroom." The essence of the model is making lecture material available to the students in the format of videos prior to the class sessions, which are devoted to concept application activities. There are a number of characteristics common to the "flipped classrooms": the educational process transforms students from passive to active learners; technology facilitates the approach; class time and homework time are inverted so that homework is done first; content is given real-world context, and class activities engage students in higher orders of critical thinking and problem-solving, or help them grasp particularly challenging concepts (Albert \& Beatty, 2014).

4. Create opportunities for mastering soft skills: in the course of the interviews, communication and presentation skills were mentioned as being equivalent to the technical skills, and sometimes even prevalent to them.

5. Pay attention to usability testing in the real-world context: software testing with end-users should be sought after.

6. Involve industry expertise: industry representatives can be invited as guest speakers and provide real-world software development assignments.

7. Overcome classroom homogeneity: multidisciplinary student teams provide exposure to working with specialists from diverse backgrounds and opportunities for communication between developers and users, which are crucial for the would-be work environment.

8. Decide on the model for integrating new types of content: for example, collaboration with programs specializing in graphical and interaction design was suggested in the case of the Department of Computing as a way of incorporating the topics from design and art, while business and marketing content was proposed to be integrated via additional disciplines from the pertinent departments or in the format of case studies highlighting digitalization examples.

9. Encourage development of skills needed to cope with the ever-changing environment: with the new tools and technologies becoming available daily, it is indispensable to be able to anticipate change and adapt to it, making the innovations part of the skill set.

10. Provide opportunities for practicing teamwork skills: teamwork has risen to a very high level among the skills demanded in the workplace during the last 
years, being prevalent to programming and other professional skills, and should therefore be honed in the classroom.

11. Concentrate on new technologies, platforms, and user interfaces: touch screens and virtual and augmented reality glasses are part of the software development process, and should be addressed in the curriculum.

12. Pursue the benefits of interdepartmental programs, which are especially pertinent in the case of UX and HCI as multidisciplinary fields drawing on design, psychology, ergonomics, management science, and business. Interdepartmental cooperation is a means of practicing software development in real-life projects within teams mingling a variety of expertise areas.

13. Take into account that the area of focus shifts from software development to business and marketing expertise as the students move closer to graduation: initially, the concentration is on technological skills, complemented with art and design, while with time business topics become more prominent.

14. Ensure that user-centricity is a run-through theme during the projects implementation: the students should be prompted to concentrate on an average end-user while developing the software.

\subsection{Research Limitations}

The present analysis was entirely performed using qualitative approaches of a semistructured interview and thematic analysis, while triangulation with a quantitative method of data collection and analysis might have been pursued.

Stemming from the qualitative nature of the research, the primary intention was to provide an in-depth view of the respondents' reasoning, beliefs, and attitudes to the studied subject of usability curriculum reform, rather than to demonstrate generalizability of the study findings to larger populations or research contexts. The accent was on grasping nuances of the study subjects' standpoints regarding revisions to the study programs that they deemed necessary to implement, and on eliciting rich accounts of their opinions. The size of the sample ( 8 respondents) is therefore validated for the nature of the research and the studied context. The specific aims of the research would have been impossible to achieve if a larger sample size had been applied.

Another limitation of the research is a lack of post-validation of the observations via a larger feedback workshop or by longer individual interviews. The limitations of the study are thus in line with the shortcomings of the chosen technique, a semi-structured in-person interview, and could be overcome by implementing still more in-depth research methods, including a focus group.

Finally, the study exclusively targeted university faculty population, while consideration of the opinions of university partners from the industry remained outside the scope of the research. An elaboration on the viewpoints of the industry partners is crucial to augment the obtained findings, and additional research should be devoted to studying it. 


\subsection{Future Research Directions}

Future research should concentrate on the separate themes that emerged from the interviews and explore them in greater depth and detail.

For example, ways of teaching user experience, usability, and user-centered design were a common theme highlighted by the participants, and should be examined separately. Aspects that require further exploration are how the topics can be made prominent in the curricula, what teaching methodologies are pertinent, and how active learning can be applied to facilitate the acquisition of the corresponding skills. It should also be examined how to integrate the themes into the content of the existing courses or how to present them in a dedicated course, how to develop practical assignments that would train the skills, and how to keep up with the rapidly developing subjects. In order to answer these questions, a focus group approach can be employed. Group interaction is likely to elicit a variety of viewpoints and insights regarding the best way of reflecting UX and usability topics in the curricula.

Another theme that merits additional attention, and should be researched in focus group format, are various methodologies of teaching UX implemented by the universities worldwide. It is not clear from the present findings, for example, how the models of intensive programs that concentrate on user interaction and graphical design can be followed within the existing curricula. Working in small groups, another international best practice, is already part of the course set-up, but further investigation of how it can be applied more intensively and on a larger scale is critical. The possibilities of MOOCs and "flipped classroom" are not self-evident from the data collected and need to be analyzed further, as a separate interview or focus group topic. The best way of incorporating software testing with actual users into the content of the courses deserves a more indepth analysis as well. Finally, practical works were a topic that was mentioned among the international best practices, but needs to be studied via a devoted in-depth interview or focus group.

Because the respondents were divided in answering the question about integrating the content from the fields of business and marketing, the controversies should be explored further. A focus group should be held to include respondents that favor and disagree with the approach, to identify the arguments put forth by the opponents in greater detail than this was possible during the original interviews. A topic that could be discussed during the focus group are the examples of integrating business and marketing content by various universities.

Ways of teaching teamwork skills should also be explored further as part of focus groups or larger-scale structured interviews, as they were ranked high by the participants answering the questions about the crucial skills demanded from the graduates and the new skills required by the job market. The questions for further research are how to adjust the curricula so that teamwork is practiced even more intensively than it currently is, in what formats to execute the skill, and how to balance this "soft skill" with the technical ones that are being taught.

The present interviews did not aim to look in-depth at how familiarity with new platforms for software development should be acquired, but this topic can be raised during 
further studies in focus groups. The questions to be addressed are the new possibilities that innovative platforms present to the software developers, how users interact with the new user interfaces, and how this should be reflected in the curriculum.

Another topic to be discussed in focus groups or expanded interviews is how to realize the benefits of interdepartmental programs. The approach seems appealing to a large number of interviewees, but the concrete mechanisms of organizing interdisciplinary studies are outside the scope of the conducted interviews. It should be clarified in further research how to establish interdepartmental cooperation, what units should be involved, how smooth interaction among them can be organized, and how the taught content should be divided among the participating departments. Attention should be paid to achieving a holistic program taught by the partnering departments, so that the curriculum is not a compilation of disparate modules, but a monolithic whole, and to delivering value via the combined curriculum, so that students benefit from the integrated courses.

An additional topic that deserves further exploration is cooperation among the universities to implement updated curricula, for example in the form of synchronized study modules.

Only one question of the interview guide concerned the impact of digitalization on the UX curriculum. However, the implications of digitalization for the curricula should be a topic of a broader discussion, that would focus on how teaching methods and content of the courses should be adjusted to take the tendency into account. Further exploration of the content of the envisioned module is also necessary. The composition of the module proposed as part of the conducted interviews should be studied in greater detail. Further research should elucidate the types of learning activities and outcomes that are expected from such module, the relative weight of the different topics suggested by the interviewees, and the ways of seamlessly integrating the content so that the module is holistic, and not an arbitrary combination of the various disconnected topics.

Although the interview findings demonstrated a consensus as to the necessity to integrate fragments of the curricula in the fields of design and art, this topic deserves further attention. A focus group could be devoted to soliciting the views on how to merge the content, what disciplines are candidates for such additions, or how to teach these topics in parallel with the computing courses. Further, it should be clarified what considerations need to be taken into account for this combination to be beneficial, how the synergy can be achieved in practice, and how to overcome artificially adding portions of the course content, so that a holistic program emerges.

One more topic on which there was a near unanimity among the respondents is the desirability of integrating topics from psychology into the usability programs. The topics outside the scope of the present study are how to review the corresponding courses to make the adjustment, how to introduce the psychological content, and how to make the transitions between the core course and the additions smooth. The same concerns adding content in the fields of communication science and information studies, which was proposed by the respondents. It is not evident from the results of the interviews which topics from communication science and information studies are deemed important to be 
included, how they should be introduced, in what format and to what extent, and what the resulting courses should look like in terms of learning activities, learning outcomes, and key modules.

The interviewees also consented that the approach for integrating technology, business, art, and design is pertinent to the disciplines they teach, differing as to the specifics, i.e., on whether accent should be placed on technology, art, and design, or on business aspects. Just like the impact of digitalization, the topic is broad and deserves a separate in-depth study. It should be investigated in what proportions each of the four proposed components should be represented, in what formats content from the different disciplines should be incorporated, how to balance the various topics, and how to achieve a holistic study program, which would not be composed of the disparate fragments, but provide a smooth learning experience to the students.

\section{Conclusions}

The aim of the research was to clarify, first, what topics are indispensable to be included in user experience courses. We analyzed the responses to the interview questions and extracted the following answer: the topics range from ensuring the best user experience, interaction design, new platforms for software development, full stack development, and software testing to team management, project management, presentation skills, academic writing, business skills, and change management.

The second research question was, what approaches to teaching UX programs can be borrowed from the experience of the universities worldwide? Analysis of the interview replies leads to the following conclusion: the techniques vary from working with new devices and platforms, intensive programs that concentrate on user interaction and graphical design, and working in small groups to MOOCs, lecture videos ("flipped classroom"), software testing with actual users, and practical works.

Third, we aspired to ascertain how applicable elements in the fields of business and marketing, design, information and knowledge management, information behavior, psychology, and communication studies can be incorporated into UX education. Based on the data collected during the interviews, we came to conclude that topics from design and art are to be integrated in the first place, followed by fragments of the curricula in the fields of psychology, business and marketing, communication science, and information studies.

Finally, we sought to answer what recommendations can be made for developing content of the courses in UX/HCI for the universities with technological profile, based on the experience of the University of Turku. The responses to the interview questions allow to reply that there are two groups of the guidelines. The first one concerns approaches to organizing the process of renewal of the courses and includes making sure that the changes suggested for implementation are motivated, deciding on the model for integrating new types of content, pursuing the benefits of interdepartmental programs, and involving industry expertise. The second group deals with the content of the disciplines. The measures proposed here range from ensuring experiential learning opportu- 
nities to considering that the area of focus shifts from software development to business and marketing expertise as the students move closer to graduation.

The key findings are that usability should be more prominent in the course content or should be the topic of a separate discipline. Further, the opinions as to the integrative model combining technology, business, design, and art within study programs were found to differ. Half of the respondents accentuated the cluster of technology, design, and art, while the other half saw potential in also including business topics.

Different models for integrating topics from business and marketing, design and art, information studies, psychology, and communication science were identified during the interviews. The views expressed can be ranked along the dimensions of content- and discipline-oriented integration and real-life integration, from approaches that support incorporating additional content as part of the existing curricula to inviting students from different departments to work together on ill-defined open-ended real-world problems.

\section{References}

Albert, M., \& Beatty, B.J. (2014). Flipping the classroom applications to curriculum redesign for an Introduction to Management course: impact on grades. Journal of Education for Business, 89(8), 419-424.

Alonso-Ríos, D., Vázquez-García, A., Mosqueira-Rey, E., \& Moret-Bonillo, V. (2010). Usability: a critical analysis and a taxonomy. International Journal of Human-Computer Interaction, 26(1), 53-74.

Altay, B. (2014). User-centered design through learner-centered instruction. Teaching in Higher Education, $19(2), 138-155$.

Andreu-Andres, M.-A., Gonzalez-Ladron-de-Guevara, F.R., Garcia-Carbonell, A., \& Watts-Hooge, F. (2018). Contrasting innovation competence FINCODA model in software engineering: narrative review. Journal of Industrial Engineering and Management, 11(4), 715-734.

Bestavros, A., Lapets, A., \& Varia, M. (2017). User-centric distributed solutions for privacy-preserving analytics. Communications of the ACM, 60(2), 37-39.

Brenner, W., Karagiannis, D., Kolbe, L., Kruger, J., Leifer, L., Lamberti, H.-J., Leimeister, J.M., Osterle, H., Petrie, C., Plattner, H., Schwabe, G., Uebernickel, F., Winter, R., \& Zarnekow, R. (2014). User, use \& utility research: the digital user as new design perspective in business and information systems engineering. Business and Information Systems Engineering, 6(1), 55-61.

Breuch, L.-A. M.K., Zachry, M., \& Spinuzzi, C. (2001). Usability instruction in technical communication programs: new directions in curriculum development. Journal of Business and Technical Communication, 15(2), 223-240.

Chandor, A., Graham, J., \& Williamson, R. (1985). The Penguin Dictionary of Computers (3rd ed.). Penguin, Harmondsworth.

Cheng, D.-Y., Chao, K.-M., Lo, C.-C., \& Tsai, C.-F. (2011). A user centric service-oriented modeling approach. World Wide Web, 14(4), 431-459.

Churchill, E., Bowser, A., \& Preece, J. (2013). Teaching and learning human-computer interaction: past, present, and future. Interactions (New York, N.Y.), 20(2), 44-53.

Cooke, L., \& Mings, S. (2005). Connecting usability education and research with industry needs and practices. IEEE Transactions on Professional Communication, 48(3), 296-312.

Corrigan, M., \& Miller, G.H. (2011). Toward a user-centric digital ecosystem. IT Professional, 13(4), $12-15$.

Costa, C.E. (2014). User centric media research challenges. Multimedia Tools and Applications, 70(1), 263265.

Dabrowski, M., \& Acton, T. (2013). The performance of recommender systems in online shopping: a usercentric study. Expert Systems with Applications, 40(14), 5551-5562.

Dijiang, H., Tianyi, X., \& Huijun, W. (2013). Mobile cloud computing service models: a user-centric approach. IEEE Network, 27(5), 6-11.

Faiola, A., \& Matei, S.A. (2009). Enhancing human-computer interaction design education: teaching affordance design for emerging mobile devices. International Journal of Technology and Design Education, 20(3), 239-254. 
Gulliksen, J., Göransson, B., Boivie, I., Blomkvist, S., Persson, J., \& Cajander, Å. (2003). Key principles for user-centred systems design. Behaviour and Information Technology, 22(6), 397-409.

Hertzum, M., \& Clemmensen, T. (2012). How do usability professionals construe usability? International Journal of Human-Computer Studies, 70(1), 26-42.

Hienerth, C., Keinz, P., \& Lettl, C. (2011). Exploring the nature and implementation process of user-centric business models. Long Range Planning, 44(5-6), 344-374.

Holtkamp, P., \& Pawlowski, J.M. (2015). A competence-based view on the global software development process. Journal of Universal Computer Science, 21(11), 1385-1404.

Huang, S.-L., \& Shiu, J.-H. (2012). A user-centric adaptive learning system for e-learning 2.0. Educational Technology and Society, 15(3), 214-225.

Koutsabasis, P., \& Vosinakis, S. (2012). Rethinking HCI education for design: problem-based learning and virtual worlds at an HCI design studio. International Journal of Human-Computer Interaction, 28(8), $485-499$.

Ludi, S. (2005). Providing students with usability testing experience: bringing home the lesson "the user is not like you." In Proceedings of Frontiers in Education 35th Annual Conference, T3G.

Mackay, W.E., \& Fayard, A.-L. (1997). HCI, natural science and design: a framework for triangulation across disciplines. In Proceedings of the $2^{\text {nd }}$ Conference on Designing Interactive Systems: Processes, Practices, Methods, and Techniques (August 1997), 223-234.

Mitchell, V., Wilson, G., Jewitt, C., Mackley, K.L., Golmohammadi, L., Atkinson, D., \& Price, S. (2020). Digital touch: towards a novel user-experience design pedagogy. Design and Technology Education, 25(1).

Monserrat, J.F., Alepuz, I., Cabrejas, J., Osa, V., López, J., García, R., Domenech, M.J., \& Soler, V. (2016). Towards user-centric operation in $5 \mathrm{G}$ networks. EURASIP Journal on Wireless Communications and Networking, 2016(1), 1-7.

Parida, V. (2018). Digitalization. In Frishammar, J., Ericson, Å. (Eds.), Addressing Societal Challenges. Luleå University of Technology, 23-38.

Parviainen, P., Tihinen, M., Kääriäinen, J., \& Teppola, S. (2017). Tackling the digitalization challenge: how to benefit from digitalization in practice. International Journal of Information Systems and Project Management, 5(1), 63-77.

Patton, J. (2007). Understanding user centricity. IEEE Software, 24(6), 9-11.

Sundblad, Y., Winberg, F., Westerlund, B., \& Lantz, A. (2006). User oriented cooperative interaction design: a multidisciplinary project course. In Proceedings of HCI Educators Workshop - Inventivity: Teaching Theory, Design and Innovation in HCI, 81-84.

Yazidi, A., Granmo, O.-C., Oommen, J.B., Gerdes, M., \& Reichert, F. (2011). A user-centric approach for personalized service provisioning in pervasive environments. Wireless Personal Communications, 61(3), 543-566.

Yelmo, J.C., del Álamo, J.M., Trapero, R., \& Martín, Y.-S. (2011). A user-centric approach to service creation and delivery over next generation networks. Computer Communications, 34(2), 209-222.

Y. Amelina holds a M. Sc. degree in Economics and Business Administration in Governance of Digitalization from Åbo Akademi University in Turku, Finland (2019) and an M.A. degree in International Economics from Zaporizhzhya Institute of Economics and Information Technologies (ZIEIT) in Zaporizhzhya, Ukraine (2005). She has taught international management, marketing, and economic development strategies at ZIEIT for 3 years and has experience working as director for international cooperation at ZIEIT and as communications manager for an ICT4D program of the Bill and Melinda Gates Foundation in Ukraine. Her research interests include managing international business competitiveness and governance of digitalization. 
E. Sutinen is Professor of Computer Science (Interaction design), leading the plug-in campus (ftlab.utu.fi) of University of Turku, Finland, in Windhoek, Namibia. After his $\mathrm{PhD}$ from University of Helsinki in 1998, Erkki was a professor at University of Eastern Finland where he founded a research group in educational technology, hosting an online $\mathrm{PhD}$ program impdet.org. Erkki has been researching educational technology, computing education, ICT4D, and co-design, supervised circa $30 \mathrm{PhDs}$, and co-authored around 300 papers. An ordained Lutheran priest, his current interests include digital theology.

S. Helle received his Master of Sciences, Electrical Engineering and Licentiate of Technology diplomas from Helsinki University of Technology, Finland, in 1987 and 1993, respectively. His main areas of interest are in usability and user interface design. He worked at Nokia Mobile Phones and Nokia Oyj in UI design and user experience related R\&D positions from 1993 to 2012. While at Nokia, he authored and co-authored several patented inventions. Since 2012, Helle has worked at University of Turku as a Senior Researcher in AR and VR related research projects, and is also involved in teaching. 


\section{Appendix 1}

\section{Responses to Question 2}

\begin{tabular}{|c|c|c|c|c|c|c|c|c|c|c|}
\hline \multicolumn{2}{|c|}{ Response } & \multirow{2}{*}{$\mathrm{N}$} & \multirow{2}{*}{1} & \multirow{2}{*}{2} & \multirow{2}{*}{3} & \multirow{2}{*}{4} & \multirow{2}{*}{5} & \multirow{2}{*}{6} & \multirow{2}{*}{\multicolumn{2}{|c|}{78}} \\
\hline $\mathrm{a}$ & $\begin{array}{l}\text { User experience and HCI skills: user-centered } \\
\text { perspective on design or development, testing with } \\
\text { the users, user interface design }\end{array}$ & & & & & & & & & \\
\hline $\mathrm{b}$ & $\begin{array}{l}\text { Working in a multidisciplinary group, teamwork } \\
\text { skills, communicating with non-developers }\end{array}$ & 5 & & $\bullet$ & & $\bullet$ & & $\bullet$ & $\bullet$ & $\bullet$ \\
\hline $\mathrm{c}$ & Purely technical specialized knowledge & 3 & & $\bullet$ & & & & & & \\
\hline $\mathrm{d}$ & Presentation skills & 1 & & $\bullet$ & & & & & & \\
\hline $\mathrm{e}$ & Technical writing skills & 1 & & & 0 & & & & & \\
\hline $\mathrm{f}$ & Applying critical thinking to interaction design & 1 & & & $\bullet$ & & & & & \\
\hline $\mathrm{g}$ & Automated testing of user interfaces & 1 & & & & $\bullet$ & & & & \\
\hline $\mathrm{h}$ & $\begin{array}{l}\text { Understanding the significance of the architectural } \\
\text { decisions }\end{array}$ & 1 & & & & & $\bullet$ & & & \\
\hline $\mathrm{i}$ & $\begin{array}{l}\text { Decisions that are connected to the software } \\
\text { attributes quality }\end{array}$ & 1 & & & & & $\bullet$ & & & \\
\hline $\mathrm{j}$ & $\begin{array}{l}\text { Ability to detect bad practices in the software design } \\
\text { and knowing how to fix them }\end{array}$ & 1 & & & & & $\bullet$ & & & \\
\hline $\mathrm{k}$ & Programming and small-scale design skills & 1 & & & & & & $\bullet$ & & \\
\hline 1 & Architectural design and requirements analysis & 1 & & & & & & $\bullet$ & & \\
\hline $\mathrm{m}$ & Project management & 2 & & & & & & & & \\
\hline $\mathrm{n}$ & Business skills & 1 & & & & & & & $\bullet$ & \\
\hline
\end{tabular}

\section{Appendix 2}

\section{Responses to Question 3}

\begin{tabular}{|c|c|c|c|c|c|c|c|c|c|c|}
\hline \multicolumn{2}{|c|}{ Response } & \multirow{2}{*}{$\frac{N}{2}$} & \multirow{2}{*}{1} & \multirow[t]{2}{*}{2} & \multirow[t]{2}{*}{3} & \multirow[t]{2}{*}{4} & 5 & \multirow[t]{2}{*}{6} & \multirow{2}{*}{ P } & 8 \\
\hline $\mathrm{a}$ & $\begin{array}{l}\text { Major change: user interaction with the new en- } \\
\text { vironments via mobile devices, graphical user inter- } \\
\text { face }\end{array}$ & & & & & & & & & \\
\hline $\mathrm{b}$ & $\begin{array}{l}\text { Change management: coping with the ever-changing } \\
\text { context of software development }\end{array}$ & 1 & & $\bullet$ & & & & & & \\
\hline $\mathrm{c}$ & User experience and usability skills & 4 & & & & & 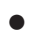 & $\bullet$ & & $\bullet$ \\
\hline d & Test automation skills & 1 & & & & & & & & \\
\hline e & Full stack web development skills & 1 & & & & & 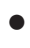 & & & \\
\hline $\mathrm{f}$ & Teamwork skills & 1 & & & & & & $\bullet$ & & \\
\hline $\mathrm{g}$ & Cloud computing & 1 & & & & & & & $\bullet$ & \\
\hline
\end{tabular}




\section{Appendix 3}

\section{Responses to Question 4}

\begin{tabular}{|c|c|c|c|c|c|c|c|c|c|c|}
\hline & sponse & $\mathrm{N}$ & 1 & 2 & 3 & 4 & 5 & 6 & & \\
\hline $\mathrm{a}$ & $\begin{array}{l}\text { No approaches/methodologies applied by the uni- } \\
\text { versities in Finland or abroad mentioned }\end{array}$ & 8 & $\bullet$ & $\bullet$ & $\bullet$ & $\bullet$ & $\bullet$ & $\bullet$ & $\bullet$ & \\
\hline $\mathrm{b}$ & $\begin{array}{l}\text { Need to learn from programs that go into design, } \\
\text { user interface design, graphic design, and user in- } \\
\text { volvement }\end{array}$ & 1 & $\bullet$ & & & & & & & \\
\hline $\mathrm{c}$ & $\begin{array}{l}\text { More exercises and group work needed instead of } \\
\text { just theoretical knowledge }\end{array}$ & 4 & & $\bullet$ & & $\bullet$ & $\bullet$ & $\bullet$ & & \\
\hline $\mathrm{d}$ & Course assistants to facilitate group work & 1 & & $\bullet$ & & & & & & \\
\hline $\mathrm{e}$ & MOOCs are worth adopting & 1 & & & $\bullet$ & & & & & \\
\hline $\mathrm{f}$ & $\begin{array}{l}\text { "Flipped classroom": video lectures followed by } \\
\text { discussion and application in the classroom }\end{array}$ & 1 & & & $\bullet$ & & & & & \\
\hline $\mathrm{g}$ & Testing with actual users highly valued & 2 & & & & $\bullet$ & & & $\bullet$ & \\
\hline $\mathrm{h}$ & $\begin{array}{l}\text { New kinds of devices and technologies to be taken } \\
\text { into account }\end{array}$ & 2 & & & & & $\bullet$ & & $\bullet$ & \\
\hline $\mathrm{i}$ & Cross-disciplinary collaboration & 2 & & & & & $\bullet$ & & & • \\
\hline
\end{tabular}

\section{Appendix 4 \\ Responses to Questions 7-9}

\begin{tabular}{llllllllll}
\hline Response & N & 1 & 2 & 3 & 4 & 5 & 6 & 7 & 8 \\
\hline
\end{tabular}

Q7

a Product development sector is a crucial area between software development and business domains, so there is no need to delve into the theory of business and marketing

b The model holds considerable potential, as monetization of the software should be considered already at development stage

c Does not see ways of directly incorporating the content into the taught course: business viability of the built software is not in focus

d A course in software business as a potential venue

e Exercise projects delivered in collaboration with the industry as a potential venue

f These topics are already present among the themes of the Capstone projects 
Response $\begin{array}{lllllllll}\mathrm{N} & 1 & 2 & 3 & 4 & 5 & 6 & 7 & 8\end{array}$

\section{Q8}

a Design and art can be integrated into the content, in particular via cooperation projects

b Graphics, design, and game art are part of the game development courses

c Yes, via applied tasks, project works, and Capstone projects, as well as having students with multidisciplinary background

d The need for components of design and art is evident in some of the Capstone project topics

\section{Q9}

a Positive about the need to borrow from topics in psychology (or recommends as a minor subject)

b Envisions ways of adopting topics from information studies, in particular concerning the ways of visualizing and expressing information

c Separate themes from communication science can be borrowed

d Media studies are already part of the curriculum

e Topics from media literacy could be useful

f Social media and information and knowledge management can be presented as applications of distributed systems in cases and exercise projects

\section{Appendix 5}

\section{Responses to Question 5}

\begin{tabular}{|c|c|c|c|c|c|c|c|c|c|c|c|}
\hline \multicolumn{2}{|c|}{ Response } & \multirow{2}{*}{$\frac{\mathrm{N}}{1}$} & \multirow[t]{2}{*}{1} & \multirow{2}{*}{2} & \multirow[t]{2}{*}{3} & & \multirow[t]{2}{*}{5} & & \multirow[t]{2}{*}{6} & \multirow[t]{2}{*}{7} & 8 \\
\hline $\mathrm{a}$ & $\begin{array}{l}\text { Students could benefit from a broader context and } \\
\text { from knowing the business issues, but it is design } \\
\text { skills and knowledge that are missing in the current } \\
\text { courses }\end{array}$ & & & & & & & & & & \\
\hline $\mathrm{b}$ & $\begin{array}{l}\text { Joint interdepartmental programs are applicable, } \\
\text { especially in the case of UX, provided that the profile } \\
\text { as the center of excellence in digital technology is } \\
\text { upheld (including interdisciplinary student teams) }\end{array}$ & 7 & & $\bullet$ & & & & & & & \\
\hline $\mathrm{c}$ & The combination is more pertinent for start-ups & 1 & & & & & & & $\theta$ & & \\
\hline
\end{tabular}




\section{Appendix 6}

\section{Responses to Question 6}

\begin{tabular}{llllllllll}
\hline Response & $\mathrm{N}$ & 1 & 2 & 3 & 4 & 5 & 6 & 7 & 8 \\
\hline
\end{tabular}

a Design issues need to be taught together with pragmatic tools: interacting with the real customers, getting information from them, and formalizing the data for interface building

b Service design as a methodology to explore

c Hands-on course with small groups and possibly a teaching assistant, focusing on UX and usability

d Basic project course for developing software should be introduced alongside the existing special and Capstone projects

e Graphical skills

f Cooperation within cross-discipline teams

g Testing software with the actual users

$\mathrm{h}$ Distributed systems and usability - via practical exercise projects in cooperation with the industry partners

i A course on requirements analysis

j Web-related courses

1

$\mathrm{k}$ An experimental course, with students trying out 1 new platforms and new input and output devices

1 Project topics in different fields related to 1 digitalization

\section{Appendix 7}

\section{Responses to Question 10}

\section{Response}

a Supported the model, but still accentuated design and art as being closer to the topic of user experience

b The approach is definitely applicable, in particular to the field of game development, and beyond its scope

c Rather than learning the suggested components, the students should be taught to interact with experts in various subject areas, and with team members having different backgrounds

d Multidisciplinary student teams implement the integrative approach working on real-world needs, but there is no structured curriculum for that

\begin{tabular}{lllllllll}
$\mathrm{N}$ & 1 & 2 & 3 & 4 & 5 & 6 & 7 & 8 \\
\hline
\end{tabular}

1

5

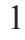

